east side of the Cascade Mountains, every stage of gradation may be traced from circular mounds, through elliptic, long elliptic, to ordinary erosion furrows and ridges.

Mr. Wallace asks in concluston whether so extensive and uniform a deposit could be due to glaciers alone, or is it necessary to suppose submergence?

In answer I would say that nothing is to me more puzzling than the drift deposits on the Pacific slope, and I suppose the same is true everywhere. The prairies about Pugit Sound have evidently been submerged during the Champlain efoch, and I suppose the mound structure to have been formed after emergence, and the exceptional perfection of the mounds in that region may be due to this fact. But there is not the slightest evidence of submergence in the mound region of Oregon. All the high, bare, grassy, hilly, eastern slopes of the Cascade Mountains are covered evenly with a pebble and bonlder drift, graduating upwards into a finer top soil. From this surface-soil are carved the mounds, which cover hill and dale so thickly that, viewed from an eminence the whole face of the country seems broken out with measles. This universal drift-covering, twenty to thirty feet thick over thousands of square miles, I know not what to call it, unless it be the moraine profonde of an icesheet.

University of Cal., Oakland, Cal, March 6

\section{JOSEPH I.E CONTE}

\section{OUR ASTRONOMICAL COLUMN}

WinNecke's COMET, 1877 , Ir.-In a note by Prof. Winnecke in M. Leverrier's Bulletin of April 13, it is remarked with respect to the elements of the comet discovered by him on April 5, "a great analogy exists between these elements and those of the comets 1827 , II, and 1852 , II., and it acquires a certain importance from the fact that the intervals are nearly equal."

The second comet of 1827 was discovered by Pons at Florence and Gambart at Marseilles, on June 20, and was observed at Floxence until July $2 I$; the original observations will be found in Astron. Nach., No, 128. The best orbit is by Heiligenstein.

The second comet of 1852 was detected by M. Chacornac at Marseilles on May 15, and was observed at Vienna till June 8. On the suggestion of d'Arrest, the elements were calculated by Hartwig, without any assumption as to the eccentricity, and the resulting orbit proved to be a hyperbola, which, as d'Arrest remarked, rendered the identity of this comet with the second of 1827 , which had been suspected by several astronomers very unlikely. Now, however, that a comet has made its appearance after a like interval with elements bearing a certain resemblance to those of the comets of 1827 and 1852 , it may not be without interest to examine into the possibility of identity a little further. The elements of the three comets may be taken to be as follow :-

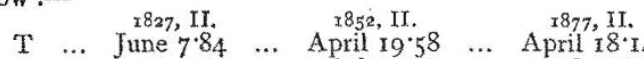

$$
\begin{aligned}
& \begin{array}{llllllllll}
\pi & \ldots & 297^{\circ} & 3 \mathrm{r}^{\prime} \cdot 7 & \ldots & 280^{\circ} & 0^{\prime} \cdot 6 & \ldots & 252^{\circ} & 0^{\prime} \cdot 0
\end{array} \\
& \begin{array}{llllllllll}
88 & \cdots & 318^{\circ} & 10^{\prime} \cdot 5 & \cdots & 3 \times 7^{\circ} & 8^{\prime} \cdot 4 & \cdots & 317^{\circ} & 51^{\prime} \cdot 3
\end{array}
\end{aligned}
$$

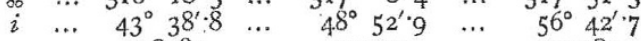

$$
\begin{aligned}
& \begin{array}{lllllll}
q & \ldots & 0.808 \overline{1} & \ldots & 0.9050 & \ldots & 0.9283
\end{array}
\end{aligned}
$$

The motion is retrograde.

It is evident from a comparison of the three orbits that if they applied to the same comet, great perturbation must have taken place between the successive returns, the line of apsides in particular having considerably retrograded, and the inclination of the orbit increased by several degrees. This suggests an examination of the path of the comet near the nodes with respect to proximity to the orbits of the planets.

Assuming the mean of the two intervals for the period of revolution, we have $24^{\circ} 93$ years, and for the semi-axis major 8.5338 , and taking as sufficient for our present purpose the perihelion distance of 1852 , the angle of eccentricity is $63^{\circ} 22^{\prime} .4$. Hence it will be found that the radius-vector at the ascending node is 10008 , which is less than 0.013 from the orbit of the earth; but to bring the two bodies together at this point the passage through perihelion must take place about September 3 , which is not the case in any of the above years. At the opposite node the radius-vector is 5.966 , not so very much greater than the radius-vector of Jupiter in the same longitude as to forbid the hope of finding a much closer approach. Accordingly on calculating the distances at different points of the orbit about the descending node, it appears on the assumption we have made with regard to the period of revolution, that in heliocentric longitude $139^{\circ}$ the comet would be distant from the orbit of this powerful planet only 0.15 of the earth's mean distance from the sun, and it would arrive in this longitude about 480 days after perihelion passage, and therefore at the end of September, 1828 , and the middle of August, 1853, but at these times the heliocentric Jongitude of Jupiter was about $232^{\circ}$ and $265^{\circ}$. respectively, and the planet was far removed from the comet in both years.

The case is a very curious one and possibly unique of its kind : similarity of elements at three epochs separated by very nearly equal intervals, and on the assumption of a corresponding perlod of revolution, a very near apparent approach to the planet which so greatly disturbs the cometary orbits, yet action to account for outstanding differences of elements, could not have taken place on either occasion of the comet's passage through the part of its orbit where great perturbation would be looked for.

A NEW COMET.-On Monday morning telegraphic intimation of the discovery of a new comet by $\mathrm{M}$. Borrelly on the evening of the 14th reached England from Marseilles, and its position was determined the same night at Mr. Barclay's Observatory, Leyton. The place is thus given in M. Borrelly's telegram :-April 14, at 9h. 30m., R.A. $16^{\circ} 3 \mathrm{r}^{\prime}$, N.P.D. $34^{\circ} 5^{\prime}$; daily motion in R.A. + $120^{\prime}$, in N.P.D. $-50^{\prime}$. On the 16 th the comet was visible enough in a large-sized Berlin "Cometensucher," but was not a bright object in such an instrument.

Observatrons at CORDOBA.-D. Dr. B. A. Gould, director of the National Observatory of the Argentine Republic at Cordoba, writes with respect to several objects to which allusion has been made in this column. Referring to $\mu$ Doradus-after remarking that it was noted as $5 \mathrm{~m}$. by Lacaille, $6 \mathrm{~m}$. by Rümker or Duniop about 1825 , and $8 \frac{1}{2} \mathrm{~m}$. or $9 \mathrm{~m}$. by Moesta, between February 1860 and January 1865, Dr. Gould says : "Our observations of it here have been on the following dates:- 1870 , Dec. $27 ; 1871$, Jan. 19,30 , March 16, April 13; 1873, March 7, on which days it was looked for in the work upon the Uranometry. Also it has been observed with the meridian circle 1874 , Jan. I2, 26; 1875, Jan. 5, 9, II, 20; 1876, Jan. 5, Feb. 12, 14. Some difficulty was experienced in recognising it on account of several other stars of the same order of brightness being situated in its immediate vicinity. The identification was confirmed, however, as soon as the equatorial telescope was mounted. The estimates of magnitude were from 8 to $8 \frac{1}{2}$, but $I$ see no reason to believe that it has changed since December I870. ** Mr. Thome estimated it as $8.3 \mathrm{~m}$. last night" (March 3). Dr. Gould proceeds, "While writing, let me add a word regarding the red star in Sculptor, mentioned in the same number of NATURE. This is one of the most intensely red stars which I know in the sky. ' But I should neither call it 'orange-red' nor 'red purple,' nor 'couleur rose,' but a brilliant scarlet. In such cases, however, different eyes bear different witness, and different individuals express themselves very differently to communicate the same idea." Dr. Gould intends at the earliest opportunity, to obtain numerical values for this and. some other stars, by means of a Zöhlner's colorimeter. The star to which we are alluding is in R.A. Ib. $21 \mathrm{~m}$. 10s. N.P.D. $123^{\circ} \times 1^{\prime} 48^{\prime \prime}$ for $1874^{\circ}$, accord. ing to observations at Cordoba.

The cluster $\gamma$ Argus, respecting which Gillis reported changes since Sir John Herschel's observations, has been photographed several times, and Dr. Cronld adds that he has similarly eight plates of $\eta$ Argus and its surrounding stais - of which a very large number are secured upon the photograph by an exposure of eight or ten minutes. 